\title{
De 'falecido' a 'coitado': a expressão de pena, dó, solidariedade e empatia em Apurinã
}

From 'deceased' to 'poor one': the expression of pity, pain, solidarity and empathy in apurinã

Laíse Maciel Barros

Universidade Federal do Pará ${ }^{1}$

Sidi Facundes ${ }^{2}$

Universidade Federal do Pará

RESUMO: As línguas do mundo comumente possuem formas lexicais ou elementos morfológicos que expressam as noções de mortes e/ou perdas, acontecimentos, em geral, carregados de emoções. Neste artigo demonstraremos o que acontece quando um morfema que indica a noção de 'finado' é usado também com outros significados na língua Apurinã. Mostraremos que a marca morfológica =nhi é usada para expressar noções como falecido, sofredor de uma ação e sentimentos de solidariedade do locutor. Diante disso, propomos uma análise que unifica esses significados a partir de sua função pragmática principal. Os usos de =nhi estão agregados a expressões nominais motivados por uma natureza semântico-pragmática que apresenta consequências também para a marcação morfossintática do alinhamento dos argumentos verbais. Para se descrever os fatos relevantes sobre os usos do $=n h i$, mostraremos suas diferentes ocorrências na estrutura das palavras em Apurinã, assim como, os variados usos e funções relacionadas a este morfema. A língua indígena Apurinã (Aruák) é falada pelo povo que possui e mesma denominação e reside no sudeste do estado do Amazonas. Este estudo é de cunho tipológico-funcional, e envolve aspectos semânticos, pragmáticos e morfossintáticos.

Palavras-chave: Língua e emoção. Apurinã (Aruák). Morfologia avaliativa.

ABSTRACT: The languages of the world commonly have lexical forms or morphological elements that express the notions of death and / or loss, events usually charged with emotion. In this article we will demonstrate what happens when a morpheme that indicates the notion of 'deceased' is also used with other meanings in the Apurinã language. We will show that the morphological marker $=n h i$ is used to express notions such as deceased, suffering from an action, and feelings of solidarity of the speaker. We propose an analysis that unifies these meanings on the basis of their main pragmatic function. The uses of $=n h i$ as it attaches to nominal expressions are motivated by a semantic-pragmatic nature that also has consequences for the morphosyntactic marking of verbal argument alignment. In order to describe the relevant facts about

\footnotetext{
${ }^{1}$ Mestranda em Letras, com área de concentração em Estudos Linguísticos, no Programa de pós-graduação em Letras da Universidade Federal do Pará. E-mail: barros.laise@gmail.com

${ }^{2}$ Professor Doutor e coordenador do Programa de Pós-Graduação em Letras da Universidade Federal do Pará.
} 
the uses of =nhi, we will show its different occurrences in the structure of the words in Apurinã, as well as the various uses and functions related to this morpheme. The Apurinã indigenous language (Arawak) is spoken by the people of the same denomination, located in the southeast subregion of the state of the Amazonas, in Brazil. This study follows a functional-typological orientation, and involves semantic, pragmatic and morphosyntactic aspects.

Keywords: Languages and emotion. Apurinã (Arawák). Evaluative morphology.

\section{Introdução}

Este artigo tem por finalidade apresentar uma análise dos usos da marca morfológi$\mathrm{ca}=n h i$ da língua Apurinã. Tal morfema é usado para expressar, nesta língua, as noções de falecido, sofredor de uma ação e sentimentos de pena ou solidariedade. Tais usos do morfema estão diretamente relacionados à natureza semântico-pragmática dessas noções.

Para entender os usos de $=n h i$, apresentaremos, primeiramente, uma descrição das suas diferentes ocorrências na estrutura das palavras em Apurinã, e, em seguida, apresentaremos os variados usos e funções relacionadas a este morfema. As análises do referido morfema são baseadas nos domínios da semântica e da pragmática, e nos estudos sobre língua e afeto de Besnier (1990). O corpus da pesquisa foi construído a partir de informações contidas em Facundes (2000) e dos dados de duas viagens ao campo realizadas em 2015. Estes dados consistem em enunciados obtidos em elicitação direta, narrativas tradicionais, relatos de experiência, e conversas espontâneas oriundas do cotidiano das comunidades. Esse material foi obtido com a ajuda de colaboradores com idade entre 24 e 55 anos e pertencentes a distintas comunidades do povo Apurinã.

Os textos e os enunciados foram transcritos por meio do programa ELAN ${ }^{3}$. Para a construção deste trabalho, contamos com o auxílio de três colaboradores: Santos, Raimundo Nonato e Erivaldo, que forneceram os dados para a pesquisa, auxiliaram nas transcrições na língua Apurinã, e fizeram a tradução dos dados para o português. Após as transcrições, foi elaborada uma lista contendo as situações de ocorrências do morfema em estudo.

Além dos textos coletados nas viagens de campo, também faz parte do corpus a narrativa kema sytukata ${ }^{4}$, interlinearizada no programa computacional FLEx ${ }^{5}$ (Fieldworks

\footnotetext{
${ }^{3}$ O ELAN é um programa de distribuição gratuita desenvolvido pelo Max Planck Institute for Psycholinguistics.

${ }^{4}$ Este texto apresenta uma narrativa tradicional do povo Apurinã e em que uma jovem Apurinã é sequestrada por uma anta que a leva para o interior da mata com o intuito de fazer dela sua esposa. A partir de então, inicia-se uma busca pela jovem por parte de seus parentes. Estes a encontram sentada num tronco de árvore com a anta ao seu lado. Os parentes da jovem matam a anta a flechada e a cacetada. Nessa ocasião, os Apurinã perceberam que a jovem estava grávida da anta. Um fato aparentemente inusitado nessa parte da narrativa diz respeito à atitude dos parentes em levar de volta consigo o pênis da anta para a aldeia, membro que mais tarde se tornaria o causador da morte de uma velhina que varria a casa onde esse membro se encontrava. $E$, finalmente, a narrativa termina quando a jovem morre durante o parto por não conseguir dar à luz ao filho da anta.

${ }^{5}$ O FLEx é um programa computacional de distribuição gratuita desenvolvido pela SIL International..
} 
Language Explorer). Essa narrativa é um dos textos do acervo de pesquisa da língua Apurinã desenvolvido por Facundes e seus alunos nos últimos 27 anos.

\section{O povo Apurinã}

O povo Apurinã pertence à família linguística Aruák e vive, principalmente, em dezenas de pequenas comunidades localizadas às margens dos afluentes do rio Purus, no sudeste do estado do Amazonas, e em comunidades situadas na rodovia 317 que liga as cidades de Rio Branco (RO) e Boca do Acre (AM), assim como nos núcleos urbanos destas duas cidades, e também nas periferias das cidades de Rio Branco ( $A C)$, Lábrea (AM), Pauini (AM), Tapauá (AM), Canutama (AM), Manacapuru (AM), e, mais recentemente, Manaus (AM) (Figura 01). O número de comunidades Apurinã cresce em decorrência das constantes migrações. De acordo com a Fundação Nacional do Índio (FUNAI) e o Instituto Socioambiental, é possível ainda encontrar Apurinã vivendo em áreas indígenas de outras etnias como na Terra Indígena Paumari do Lago Marahã, Terra Indígena Torá, Terra Indígena Roosevelt (Cinta-Larga) e terra indígena Jamamadi do Lourdes, em virtude do casamento entre os Apurinã com membros destas outras etnias.

Figura 01: Fonte: Lima-Padovani (2016)

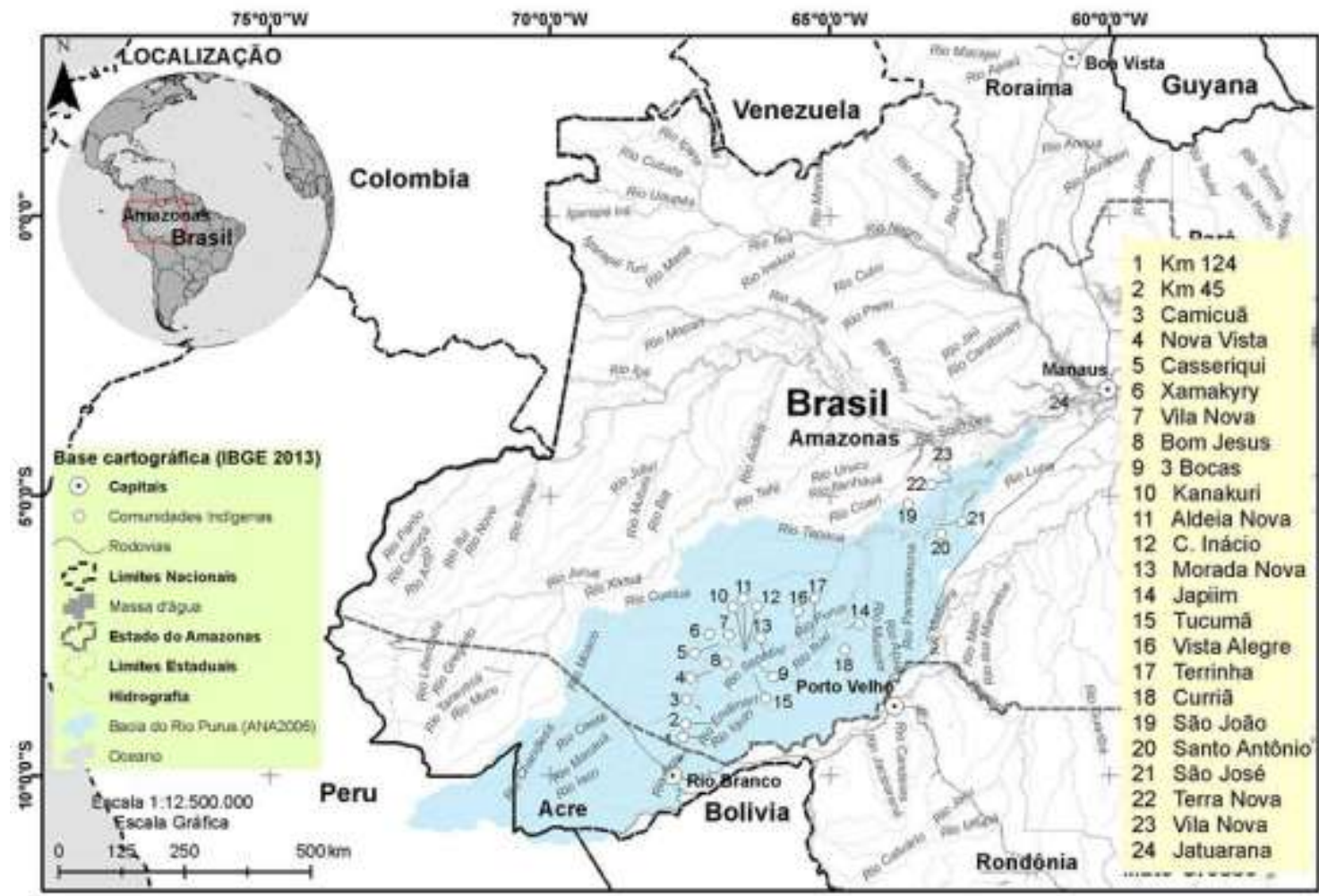




\section{0 morfema $=n h i$}

Em Facundes (2000) há uma análise preliminar sobre o morfema =nhi, descrito como uma possível marca do papel semântico de paciente do sintagma nominal (argumento do verbo) no qual ele é empregado. Segundo o autor, a marca morfológica pode anexar-se a bases nominais, pronominais ou a bases de verbos intransitivos.

Observamos, a seguir, alguns exemplos ${ }^{6}$ da língua Apurinã extraídos do texto narrativo kema sytukata e de enunciados obtidos por meio de elicitação e conversas espontâneas.

(1)

a) Ø-imata-pe-ru uwa hãtaku-ru=nhi

3.SG.M-copular-PFTV-3.F.O 3.SG.F jovem-F=AFET

'ela (anta) havia copulado com ela (a jovem)'

b) iie ypyryry-ta txa-pe-ry ywa kema=nhi ütany-ri=nhi

DEM cacetar-VBLZ AUX-PFTV-3M.O 3.SG.M anta=AFET esposo-F=AFET

- Cacetaram a coitada da anta'

c) ywa, kema hãke-ry inhinhĩa, uwa=nhi u-awãkytek-inhi-ry

3.SG.M anta filho-M então 3.SG.F=AFET 3.SG.F-dar à luz- GER-3.M.O

'A coitada a parir o filho da anta'

d) Inhinhĩã, arywatxa ywa kema hãkery iie uka txa-pe-ru uwa assim pois.é 3.SG.M anta filho-M DEM matar AUX-PFTV-3.F.O 3.SG.F

hãtaku-ru=nhi jovem-3.F=AFET

'Assim, ele, o filho da anta matou a coitada da moça'.

e) Ywa kyky ketapy-ry $\underline{\tilde{a} k i t i=n h i}$

3.SG.M homem atirar-3.O.M onça=AFET

'O homem atirou na onça'

f) $\underline{N \text {-atukyri }=\text { nhi }} \quad$ ikietary awiri.

1.SG-avô=finado cheirar-3.SG.M rapé

'Meu finado avô cheirava rapé'

\footnotetext{
${ }^{6}$ Abreviações usadas nos exemplos apresentados neste trabalho: AFET- Afetado; AUX-Auxiliar; DEM- Demonstrativo; ÊNF- Ênfase; F- Gênero Feminino; GER-Gerúndio; M- Gênero Masculino; PFTV- Aspecto Perfectivo; POSSD- Possuído; PRED- Predicativo; REFLX- Reflexivo; SG- Singular; VBLZ- Verbalizador; 1- Primeira Pessoa; 3- Terceira Pessoa.
} 
Os exemplos (1a-d), trechos da narrativa kema sytukata, apresentam usos distintos do morfema $=n h i$. Os trechos mostram alguns acontecimentos após o sequestro da jovem moça apurinã realizado por uma anta, isto é, a cópula entre a anta e a jovem, a vingança dos parentes ao encontrarem o animal, e, por fim, o parto e morte da jovemA. Ao observarmos os exemplos, percebemos que é claro que a jovem (hãtakuru) e a anta (kema) são marcadas como sofredoras (pacientes) de determinadas ações. Isso motivou Facundes (2000) a descrever =nhi como marca do papel semântico de paciente. Por outro lado, é perceptível também uma certa sensibilidade por parte de quem narra a história e que demonstra compaixão, principalmente em relação à jovem, vítima das ações da anta. Isso aparece na tradução para o português com o uso do termo "coitada". Do mesmo modo, em (1.e) e (1.f) o morfema =nhi denota o sofredor e a marca de finado, respectivamente. Assim, o referido morfema apresenta mais de um único sentido: um semântico, outro pragmático.

Como dito anteriormente, Facundes (2000) considerou o morfema =nhi como um marcador de afetação e como um indicador do papel semântico do verbo. No entanto, uma análise da função real desse morfema em termos de papéis semânticos, como observado nos exemplos acima, não contempla todos os seus usos. Quando esse morfema marca uma certa perspectiva do falante em relação ao elemento referido pelo sintagma nominal marcado por =nhi, há não simplesmente o significado semântico paciente desse sintagma nominal na sentença, mas também, um aspecto subjetivo expressando a perspectiva do falante, portanto uma informação do tipo pragmático. Mais adiante tentaremos ver como é possível apresentar uma análise coerente deste morfema que dê conta de ambos os significados, semântico e pragmático.

Veremos, a seguir, a descrição da distribuição do morfema =nhi na estrutura das palavras em Apurinã e, posteriormente, mostraremos os vários usos e funções associados a esse morfema.

\subsection{A distribuição de =nhi em Apurinã}

O morfema =nhi ocupa a posição final na estrutura de palavras do Apurinã, ocorrendo somente com pronomes ( $2 a-b)$ e nomes ( $2 c-f)$ da língua. Neste sentido, esse morfema tem como escopo não a palavra, mas sim todo o sintagma nominal, portanto comportando-se como um elemento clítico. Ao contrário de Facundes (2000), não atestamos ocorrências desse morfema em verbos. É provável que os casos em que o =nhi, supostamente, ocorreria com verbos em Facundes (200) na verdade eram instâncias de um outro morfema, o gerúndio =inhi.

(2)

- Ocorrência com pronomes

a) $\underline{Y w a=n h i} \quad$ suuwaka-pe-wa.

3SG.M=AFET cortar-PFTV-REFLX 
'Ele se cortou'.

b) $Y w a=n h i \quad$ uka-pe-wa.

3SG.M=AFET matar-PFTV-REFLX

'Ele se matou'.

- Ocorrência com nomes

c) Sytu=nhi ipỹ-pe

mulher=AFET ferir-PFTV

'A mulher está ferida'.

d) $\mathrm{N}$-atukyri=nhi ikieta-ry awiri.

1SG-avô=AFET cheirar-3SG.M rapé

'Meu finado avô cheirava rapé'.

e) Pupỹkari=nhi kakaru-pe.

Índio=AFET ferir-PFTV

'O índio está ferido'

f) Paraka=nhi iri-pe

casa=AFET cair-PFTV

'A casa caiu'

\subsection{Os usos e funções do =nhi}

Como os dados acima já sugeriram e os demais dados abaixo demonstrarão, a marca morfológica $=n h i$ tem as seguintes funções: marcar o sofredor ou resultado de uma ação, marcar o refente como finado/falecido, e, por fim, marcar a expressão do sentimento de pena, dó ou solidariedade.

Para denotar alguém que sofreu ou é resultado de ação, o =nhi se junta aos termos sintáticos - sujeito ou objeto - no interior da frase. Quando marca o sintagma nominal sujeito, esse morfema aparece com sujeito reflexivo e com sujeito paciente, sendo este animado ou inanimado. Já quando marca o sintagma nominal objeto, o =nhi ocorre com objetos pacientes animados/inanimados de verbos transitivos.

Em relação ao uso de =nhi com o sujeito, não houve ocorrência de =nhi marcando sujeito agente de um verbo transitivo a não ser que este verbo expresse uma voz reflexiva. Deste modo, o sujeito, simultaneamente, cometendo e recebendo a ação, terá a companhia do morfema marcando o sofredor da ação, como podemos observar nos exemplos $(2 a-b)$, mostrados anteriormente, repetidos em (3): 
(3)

a) Ywa=nhi suuwaka-pe-wa.

3SG.M=AFET cortar-PFTV-REFLX

'Ele se cortou'.

b) Ywa=nhi uka-pe-wa.

3SG.M=AFET matar - PFTV - REFLX.

'Ele se matou'.

c) Amarinhi=nhi ypããkaka

criança=AFET bater

'A criança se bateu'.

d) Anãpa=nhi ywa-nhika akytsaka-pe-wa

cachorro=AFET 3SG.M-comer morder-PFTV-REFLX

'O cachorro se mordeu'.

Entretanto, quando o sujeito intransitivo é paciente, tanto animado como inanimado, a ocorrência do =nhi é frequente, como mostram os exemplos (4a-f). Do mesmo modo, o morfema ocorre com os objetos (animados e inanimados), como podemos observar em $(4 g-j)$, a seguir.

(4)

- Com sujeito paciente animado.

a) $\underline{k y k y=n h i} \quad$ ipỹpe

homem=AFET machucar-PFTV

'O homem está machucado'.

b) Pupỹkari=nhi iripe

índio=AFET cair-PFTV

'O índio caiu'.

c) $\tilde{A} k i t i=n h i \quad$ ipỹpe

Onça=AFET morrer-PFTV

'A onça morreu'.

- Com sujeito paciente inanimado

d) Paraka=nhi iripe

casa=AFET cair-PFTV

'A casa caiu'. 
e) Ny-takari=nhi ipỹpe

1SG-planta=AFET morre-PFTV

'Minha planta morreu'.

f) $\mathrm{Ny-kupiti=nhi}$ irepe.

1SG-pote=AFET cair-PFTV

'Meu pote caiu'.

- Com objeto paciente animado

g) Ywa kyky ketapy-ry ãkiti=nhi.

3SG.M homem atirar-3SG.M onça=AFET

'O homem atirou na onça'.

h) Aamana pytẽkapere kyki=nhi

árvore matar homem=AFET

'A árvore matou o homem'.

i) kyky kyatapere hãty kyki=nhi ywa ukapere ywa=nhi

homem atirar um homem=AFET 3.SG.M matar 3.SG.M=AFET

'O homem atirou em outro homem e ele o matou'.

- Com objeto paciente inanimado

j) Amarinhi kapyrinhi-ka-pe-ry mekutxi=nhi

criança quebrar-ÊNF-PFTV-3.SG.M remo=AFET

'O menino quebrou o remo'.

Além do uso como marcador do argumento afetado pela ação, o morfema =nhi é usado também para atribuir o sentido de "finado" na língua, portanto, a utilização do morfema indica alguém já falecido, como mostram os exemplos em (5):

(5)

a) Itxa-ka-ta kerywaku ywa Awã̃=nhi kanawa-te ywãtãi dizer-ÊNF-VBLZ o que é 3.SG.M Awãĩ=AFET canoa-POSSD então ywã̃-mukarykanu uwa xirĩ-pe-ka-ta. então-meta 3.SG.F baixo-PFTV-ÊNF-VLBZ

'A canoa do finado Awãĩ falou, e foi pra lá, baixando o rio'

b) Na-tukyri=nhi imata-ry ixipuãt-inhi.

1SG-avô=AFET gostar-3SG.M cantar-GER

'Meu finado avô gostava de cantar'. 
c) Na-tukyri=nhi kama-ry katarukyry

1SG-avô=AFET fazer-3.SG.M farinha

'Meu finado avô fazia farinha'.

d) Na-tukyri=nhi ikieta-ry awiri

1SG-avô=AFET cheirar-3.SG.M rapé

'Meu finado avô cheirava rapé'.

e) Raimundi=nhi kariwa puião putxika-ry kãkỹte iapuku

Raimundo=AFET não.índio muito visitar-3.SG.M povo casa

'O finado Raimundo visitava muito as comunidades dos Apurinã'.

Finalmente, o último uso atestado para $=n h i$ diz respeito à atitude do falante, na qual há o sentimento de dó ou solidariedade, sua empatia com relação a algo já mencionado. Os exemplos em (6) mostram essas ocorrências:

(6)

a) Kamatinari=nhi kyky imã-ã-ta-pe

coitado=AFET homem colocar-água-VBLZ-PFTV

'O coitado do homem caiu na água'

b) Uwa-piti=nhi sytu awakykary amarinhi

ela-muito=AFET mulher parir criança

'Acoitada da mulher finalmente teve a criança'

c) Kamatinari=nhi pupỹkary ketapeẽka

coitado=AFET índio tiro

'O coitado do índio levou um tiro'

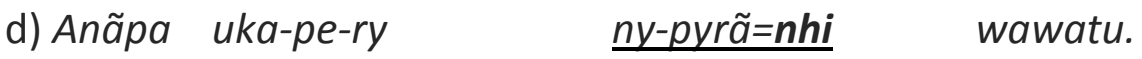

cachorro matar-PFTV-3.SG.M 1SG-criação=AFET papagaio

'O cachorro matou meu pobre papagaio'

Tendo identificado esses três usos do morfema =nhi, marcando o indivíduo afetado pela ação, alguém já falecido (finado), ou um sentimento de dó ou pena na perspectiva do locutor, a questão é se tais têm em comum que motivaria serem marcados por um mesmo morfema. A resposta é que os dois primeiros indicam um posicionamento psicológico do locutor em relação ao argumento marcado por $=n h i$. $O$ grau em que algo ou alguém é afetado em um evento pode variar, ao menos em parte, dependendo de como o evento é percebido pelo locutor; e certamente a noção de dó e pena está completamente ligada à subjetividade desse mesmo locutor. Resta então explicar como chamar alguém de "finado" 
pode depender da subjetividade do locutor. A explicação para isso, a própria estrutura da língua se encarrega de oferecer: estruturalmente, a presença de $=n h i$ é sempre opcional. Portanto, o falante opta em usar ou não a marca morfológica, e esta opção é orientada pelo apreço do falante em relação ao elemento afetado expresso no enunciado, como podemos observar nos exemplos a seguir:
a) Kupiti pataka
pote quebrar
'O pote quebrou'
Ny-kupiti=nhi pataka-pe-ka
1.SG-pote=AFET quebrar-PFTV-ÊNF
'Meu pote quebrou'

Nos exemplos (7a-b) fica evidente que a escolha do uso do morfema =nhi expressa 0 sentimento do falante em relação a um determinado objeto, neste caso um pote. Em (7a), por se tratar de um pote qualquer, não há a marca morfológica, diferentemente do exemplo (7b), em que o pote quebrado pertencia ao falante, pelo qual ele tinha um certo apreço. Esta expressão de empatia contida no uso do =nhi foi inicialmente constatada por meio de conversas com uma colaboradora durante uma sessão de elicitação de dados. Na ocasião, nos referíamos a um homem que teria sofrido um acidente. A colaboradora informou que poderia dizer em Apurinã das seguintes maneiras: kyky kurĩa (homem morrer) 'o homem morreu', para se referir a homem desconhecido, e kykinhi kurĩã (homem-AFET morrer) 'o pobre homem morreu') para se referir a alguém conhecido com quem se convivia cotidianamente, um membro da comunidade ou um familiar, entre outros, por quem se tinha um sentimento de afeto.

Tendo identificado os três usos de =nhi em Apurinã, podemos então citar um estudo feito por Taylor (2010), o qual aponta em Baniwa, língua também pertencente à família Aruák, um morfema que pode ser associado a um sintagma nominal, ao qual esse morfema dá o status de 'caduco'. Trata-se de -mi, morfema que exprime algo que deixou de existir, que já não funciona e não é mais válido. E menciona, para efeito de exemplificação, que um termo utilizado para se referir a uma canoa que tenha sido queimada ou perdida, levará obrigatoriamente $\mathrm{o}-\mathrm{mi}$. $\mathrm{O}$ autor diz ainda que o referido morfema pode ser reconhecido, em Baniwa, em algumas lexicalizações como em: iñaimi 'demônio' (iñai, espírito da mata antropófago, possivelmente um defunto vítima de uma guerra entre tribos), e héeñami 'roça abandonada'.

Este mesmo morfema foi também atestado por Ramirez (2001), também em Baniwa, e classificado como sufixo nominal detrimental, já que o mesmo apresenta um valor separativo. Por exemplo, nomes para expressar algo como o galho da árvore desprendido, farelo de tapioca no fundo do saco, entre outros, terão em sua estrutura a presença de mi. Segundo o autor, o sufixo é frequente em termos de parentesco para indicar que o possuidor está morto, como em: Pedułu iitumi 'filha do finado Pedro'. Dessa forma, de acordo com Ramirez (2001), o -mi é utilizado sempre que a relação possuidor-possuído for 
quebrada, ou seja, quando há a separação entre os elementos, ou a morte de um dos dois. Assim, o autor conclui que o sufixo é a marca ideal para o abandono, o deteriorado, o veIho, o caduco ou o morto. Na acepção de denotar a noção de 'finado' -mi e =nhi são morfemas que compartilham a mesma base semântica, semelhanças atribuídas ao fato de Baniwa e Apurinã serem línguas pertencentes à mesma família (Aruák), levando-nos a crer que tais formas podem ser cognatos nas duas línguas.

\subsection{A linguagem e o caráter afetivo: =nhi e a teoria linguística}

Embora a relação entre linguagem e as emoções transmitidas pelos falantes no momento da fala seja predizível nos postulados funcionalistas, já que este admite que fatores pragmático-discursivos sejam necessários para uma compreensão adequada da natureza da linguagem humana, seguir as orientações de uma gramática descritiva funcional não foi suficiente para entender os vários usos do morfema em estudo por meio da visão estritamente gramatical. Aparentemente, há carência de referências na literatura linguística que examinem a relação entre gramática e a expressão de emoções. A gramática tipicamente é vista como associada a alguns domínios semânticos que não incluem atitudes ou emoções. Desta forma, buscamos contribuição em mais dois campos da linguística para guiar nossas análises, o pragmático e o discursivo. Ambos voltados para as formas e intenções de usos dos elementos linguísticos.

A descrição e análise dos usos e funções do morfema =nhi indicam que algumas formas gramaticais só podem ser entendidas completamente se forem estudadas por meio da análise de suas funções no contexto discursivo, e que os usos dessas formas podem estar associados, inclusive, a textos que se encaixam em tipos diferentes de discursos (BIBER, CONRAD e REPPEN 1998). No caso do =nhi, ficou claro o papel da empatia do locutor na escolha de usar ou não o morfema. Assim, consideramos importante examinar alguns estudos que apresentam a descrição linguística levando em consideração aspectos de caráter subjetivo.

Sobre a expressão do caráter emotivo na linguagem, Besnier (1990) afirma que a noção de sentido linguístico apresentada por Lyons (1977) está ligada a três componentes: o sentido descritivo, o sentido social e o sentido expressivo (afetivo ou emocional), este último representando a fala ou a escrita emocional, humor, disposição e atitudes voltadas para o contentamento de mensagens e o contexto comunicativo. Os sentidos afetivos são vistos em codificações das emoções da fala, em que o interlocutor decodifica as mensagens verbais que são precedentes da intencionalidade, de propriedades individuais, (BESNIER, 1990).

Esse autor mostra que em algumas línguas, como Samoana ${ }^{7}$ e Tonga ${ }^{8}$, encontra-se uma forma diminutiva de um determinado pronome em primeira pessoa que pode ser u-

\footnotetext{
${ }^{7}$ Língua oficial de Samoa.

${ }^{8}$ É uma língua polinésia falada no reino de Tonga e outros países como: Zâmbia, Zimbábue e Moçambique.
} 
sado para induzir a empatia e marcar também a autodepreciação. E ainda afirma que em Samoana o experienciador de emoções frequentemente é decodificado com um modificador locativo atrelado ao verbo, em vez de se agregar ao sujeito gramatical; o mesmo padrão é atestado em lídiche e Kaluli, esta última é uma das línguas faladas na Papua Nova Guiné (cf. Talmy, 1985).

Segundo Besnier (1990), línguas que não apresentam variados recursos pragmáticos possuem elementos (como pronomes e artigos, por exemplo) que podem igualmente conter os sentidos de empatia e de depreciação, mencionados acima. Estes sentidos são geralmente transmitidos por meio do afeto.

O referido autor ainda afirma que processos lexicais como sinédoque e metonímia estão frequentemente envolvidos na manipulação dos significados afetivos. Da mesma forma, outros processos metafóricos possuem dimensões afetivas, pois, em muitas culturas, as falas em que há processos emocionais estão repletas de metáforas. E algumas áreas marginais do vocabulário de muitas línguas, como ideofones e onomatopeias, são ricas em significado afetivo. Por fim, destaca que os falantes expressam suas emoções por meio da fala que, por sua vez, é inseparável dos atos sociais, ou seja, do contexto que engloba as situações em que ela é proferida. Essas noções de intencionalidade, empatia, mencionadas por Besnier, são perfeitamente compatíveis com as funções do morfema =nhi da língua Apurinã.

\section{Conclusão}

Neste artigo tratamos da marca morfológica =nhi e apresentamos a sua distribuição na estrutura na língua Apurinã. Verificamos que, quanto ao aspecto morfossintático, o morfema ocupa a posição final na estrutura das palavras e ocorre com pronomes e nomes. No que diz respeito ao aspecto semântico, pragmático-discursivo, atestamos as funções de marca de afetação e finado, descritas por Facundes (2000), e observamos que além dessas, =nhi também é usado para expressar empatia, solidariedade por parte do falante no momento do discurso, demonstrando que em Apurinã a afetividade pode ser expressa na língua por meio de uma categoria morfológica, como apontado em Besnier (1990).

Estes sentidos que envolvem o morfema estão diretamente relacionados à individualidade do falante, pois há a manifestação de um sentimento, e, assim, torna-se presente a intenção do mesmo, a emoção e a sensibilidade transmitidas por meio do discurso. E é com observações como estas sobre o discurso que podemos compreender os diversos usos e funções presentes nas línguas humanas, avaliando o uso da linguagem sob diferentes visões e diferentes entendimentos, examinando como o uso da linguagem é influenciado por contribuições individuais dos participantes, e, do mesmo modo, atentando para os efeitos do uso da língua que têm implicações para as identidades e relações sociais, como afirma Paltridge (2006). 


\section{REFERÊNCIAS}

BIBER, Douglas, CONRAD, Susan e REPPEN, Randi. Corpus Linguistics. Investigating Language Structure and Use. Cambridge: Cambridge University Press,1998.

FACUNDES, Sidney da Silva. The Language of The Apurinã People Of Brazil (Maipure/Arawak). Nova York, Búfalo: Faculty of the Graduate School of State University of New York at Buffalo (Tese de Doutorado), 2000.

APURINÃ. Disponível em: https://pib.socioambiental.org/pt/povo/apurina/1512. Acesso em 25 de setembro de 2017.

LIMA-PADOVANI, Bruna Fernanda Soares de. Levantamento Sociolinguístico do Léxico da Língua Apurinã e sua contribuição para o conhecimento da cultura e história Apurinã (Aruák). Dissertação de Mestrado. Universidade Federal do Pará, Belém: 2016.

LYONS, J. Semantics. Vol 1. Cambridge: Cambridge Univ. Press. 1977.

PALTRIGDE, Brian. Discourse Analysis: an introduction. Continuum: London, 2006.

RAMIREZ, Henri. Línguas Arawak da Amazônia Setentrional. Manaus: EDUA, 2001.

TAYLOR, Gerald. O 'caduco' e o 'frustrativo' nas línguas Baniwa di lçana e Nheengatu (Alto rio Negro, Brasil). In CARLIN, Eithne B. VAN DE KERKE, Simon (eds.) Linguistics and Archaeology in the Americas. The Historization of Language and Society. Leiden: Brill, 2010.

TALMY, L. Lexicalization patterns:semantic structure in lexical forms. 1985 